\title{
Effects of Nd:YAG Laser Irradiation on Root Canal Dentin Wall: A Scanning Electron Microscopic Study
}

\author{
SAMIRA ESTEVES AFONSO CAMARGO, M.Sc., MARCIA CARNEIRO VALERA, M.Sc., Ph.D., \\ CARLOS HENRIQUE RIBEIRO CAMARGO, M.Sc., Ph.D., MANUELA BAFINI FONSECA, and \\ MARCIA MACIEL MENEZES, M.Sc., Ph.D.
}

\begin{abstract}
Objective: The purpose of this study was to evaluate, by scanning electron microscopy (SEM), the effects of Nd:YAG laser irradiation applied perpendicular or parallel to the root canal dentin wall. Methods: Thirty human teeth were divided into two groups: Group A (20 roots), laser application with circular movements, parallel to the dentin root surface; and Group B (10 roots), roots cut longitudinally and laser applied perpendicular to the root surface. Group A was subdivided into A1 (10 roots), laser application with $100 \mathrm{~mJ}, 15 \mathrm{~Hz}$ and $1.5 \mathrm{~W}$; and $\mathrm{A2}(10$ roots) with $160 \mathrm{~mJ}, 15 \mathrm{~Hz}$, and $2.4 \mathrm{~W}$. Group B was subdivided into B1 (10 hemisections) and B2 (10 hemi-sections) with parameters similar to $\mathrm{A} 1$ and A2. Four applications of 7-sec duration were performed, with a total exposure of $28 \mathrm{sec}$. SEM evaluations were made in the cervical, middle, and apical thirds, with $500 \times$ and $2000 \times$ magnifications. Morphological changes scores were attributed, and the results were submitted to Kruskal Wallis statistical test (5\%). Results: Significant statistical differences were found between groups A and B $(p=0.001)$. In groups A1 and A2, few areas of dentin melting were observed. In groups B1 and B2, areas of melting dentin covering dentin surface were observed. Conclusions: It was concluded that intracanal laser application with circular movements (parallel to the surface) produces limited morphological changes in root canal dentin wall.
\end{abstract}

\section{INTRODUCTION}

$\mathbf{L}$ ASER THERAPY IN ENDODONTICS has shown different effects when applied inside root canals, and Nd:YAG laser application provides coalition, recrystallization, and melting of the dentin. ${ }^{1-4}$ These alterations can change dentin permeability, decreasing fluids penetration inside dentin tubules. ${ }^{5-7}$

However, studies that evaluate laser irradiation on dentin show great variability in dentin morphological changes because varying parameters are used. Additionally, the morphology of root canals also influences the laser performance in dentin wall. Laser energy emission cannot be perpendicular to dentin walls, and as more energy is available in the axial direction of the optic fiber, less or no energy can be available when the tip of the fiber is not perpendicular to the working area. ${ }^{6,8}$ Anic et al. ${ }^{6}$ verified that the cervical third of specimens submitted to the laser showed larger morphologic alteration due to absence of dental crown, which allowed perpendicular orientation of the fibers in the root canal walls during the fiber removal. In the middle third of the canal, the fiber was positioned parallel to the dentin wall, promoting few morphologic alterations.

When the optic fiber is parallel to the root canal wall, the fiber side is in contact with wall, making difficult to quantify how much energy is liberated to the dentin surface. ${ }^{9}$ To improve fiber tip contact with dentin walls, circular movements are used promoting better laser light incidences. ${ }^{9}$ However, the extension and diameter of root canal can difficult direct contact of fiber tip with the dentin walls.

Anic et al. ${ }^{10}$ verified that dentin surface irradiated with $\mathrm{Nd}$ :YAG laser emitted at right angle showed coalition, recrystallization and a glazed surface covered with superficial fused and ablated dentin drops.

The purpose of this study was to evaluate in vitro the effects in the dentin walls of perpendicular and parallel application of

School of Dentistry, Paulista State University, UNESP, São José dos Campos, São Paulo, Brazil. 
pulsed Nd:YAG laser. Different energy intensities were used in the laser application and the evaluations were made by scanning electron microscopic.

\section{MATERIALS AND METHODS}

Thirty single-rooted human teeth were used in this study; after the extraction they were stored in physiological saline solution until use. Each tooth had been radiographed in order to select specimens with single canal, without curvatures and with similar anatomical forms.

The crowns of the teeth were cut with carburundum discs standardizing the root lengths to $16 \mathrm{~mm}$. The root canals were prepared by a standardized step-back serial technique. The canals were enlarged with size no. 50 file (Maillefer, S.A., Swiss), and were irrigated with of $1 \%$ sodium hypochlorite solution (Biofórmula Tecnofarma S.J. Campos, SP, Brazil) after each instrument was changed. The smear layer was removed with EDTA applied for 3 min inside root canals, followed by a final flush with $10 \mathrm{ml}$ of $1 \%$ sodium hypochlorite.

The roots were then divided into groups (Fig. 1).

Groups A and B: the root canals were aspirated and Nd:YAG laser was applied in dentin walls. For the Nd:YAG laser application the PulseMaster 600 IQ apparatus (Dental American Technologies, Inc., Corpus Christi, TX) was used. The laser beam was conducted by $320-\mu \mathrm{m}$-diameter optical fiber and by contact mode. For laser-light orientation, a light guide coupled to the apparatus was used which was composed of a low-intensity helium-neon laser (with wavelength of $632.8 \mathrm{~nm}$ ).

In group A (20 roots), the laser energy was delivered by introducing the optic fiber into the total length of the root canal starting the irradiation from the apex, proceeding in the whole extension of the root canal, with circular movements, for $7 \mathrm{sec}$. This procedure was repeated four times, with a total exposure of $28 \mathrm{sec}$.

In group B (10 roots), after the root canal preparation, the roots were sectioned longitudinally in the bucco-lingual plane using a thin carborundum disc and a slow-speed handpiece providing a total of 20 specimens. Before the laser treatment, the specimens were washed for one minute with EDTA to remove possible debris formed during the cut. In this group the laser was applied with the optic fiber tip perpendicular to dentin surface, from the apical to cervical third in $7 \mathrm{sec}$. This procedure was repeated four times, with a total time exposure of 28 $\mathrm{sec}$. The roots of groups A and B were subdivided, according to energy intensity, into groups A1, A2, B1, and B2.

In groups A1 (10 roots) and B1 (10 hemi-sections), the laser irradiation was performed with $100 \mathrm{~mJ}, 15 \mathrm{~Hz}$, and $1.5 \mathrm{~W}$. In groups A2 (10 roots) and B2 (10 hemi-sections), the parameters used were $160 \mathrm{~mJ}, 15 \mathrm{~Hz}$, and $2.4 \mathrm{~W}$.

After laser treatment of the specimens, they were observed under a scanning electron microscopic and for this, the roots of the group A were sectioned in the bucco-lingual plane utilizing a thin carborundum disc and a slow-speed handpiece. All specimens were then serially dehydrated in ethanol solutions, $25 \%$, $50 \%, 75 \%$ (20 min each), 95\% (30 min), and 100\% (60 min). The specimens were mounted on metallic stubs, sputter-coated with gold-palladium, and observed under scanning electron microscopy (SEM; JEOL model JSM5310, Tokyo, Japan).

The analyses were made with magnifications of $500 \times$ and $200 \times$, verifying morphological changes produced on dentin walls after the use of different laser parameters and methods of application. Descriptive qualitative and quantitative evaluations were made attributing scores in agreement with the presence of dentin walls morphological changes, as follows:

Score 0 , absence of dentin melting areas, open dentin tubules

Score 1 , less than $50 \%$ of the dentin tubules coated by dentin melting

Score 2, more than $50 \%$ of the dentin tubules coated by dentin melting

Score 3, dentin melting with rare open dentin tubules

The scores were tabulated and submitted to statistical analysis by Kruskal-Wallis method with $5 \%$ of probability. For the

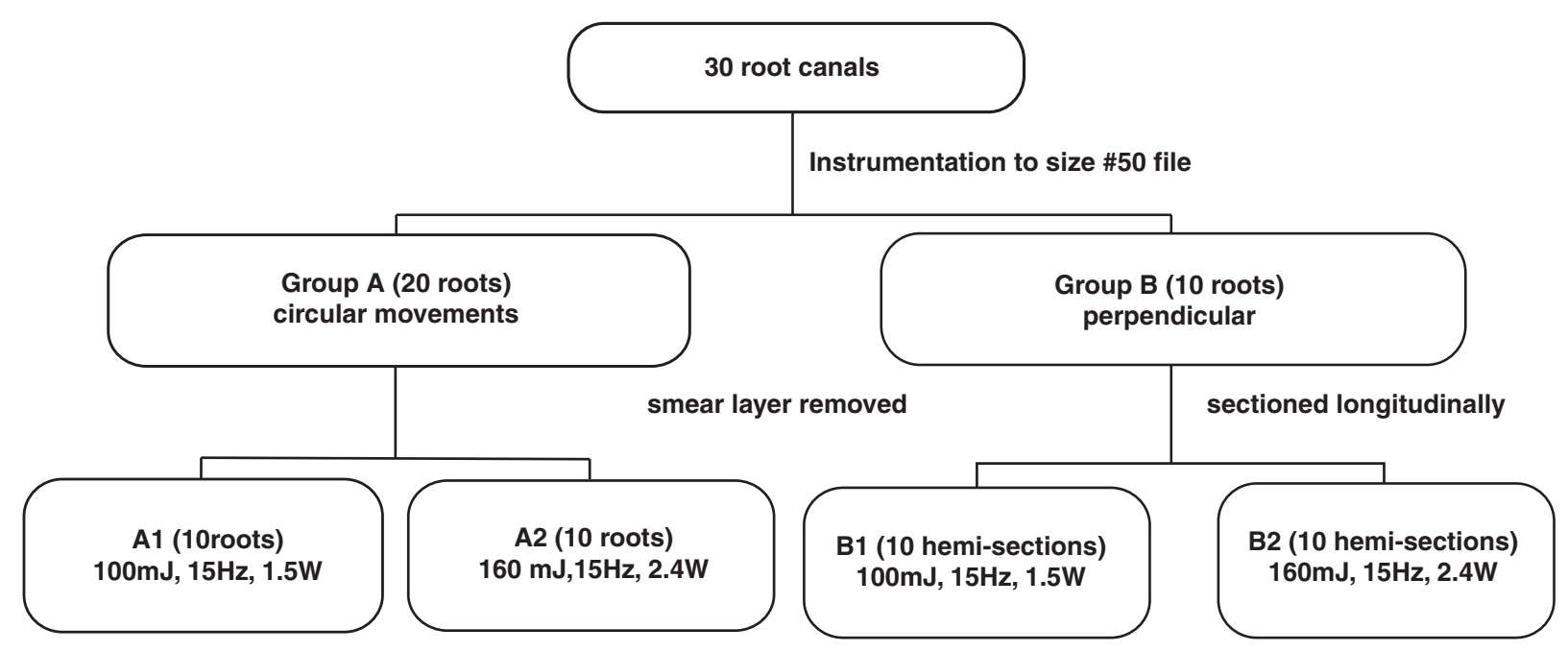

FIG. 1. Schematic representation of methodology. 


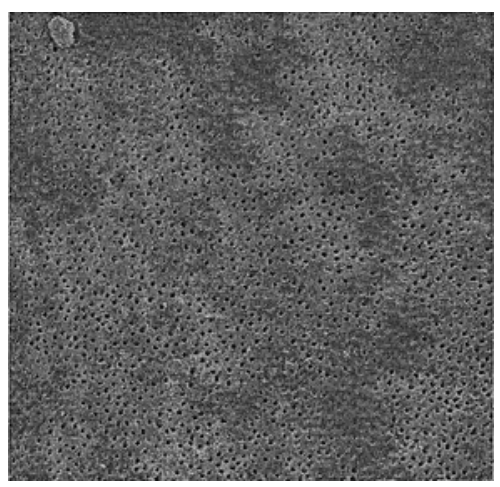

FIG. 2. Group A1 (circular/100 mJ, $15 \mathrm{~Hz}$ and $1.5 \mathrm{~W}$ ) cervical third $(500 \times)$.

evaluation among the root thirds, the Multiple Comparison test of Dunn was used (5\%).

\section{RESULTS}

In group A, in which laser application was performed inside root canals using circular movements (parallel to the surface), few areas of dentin melting were observed, with few irradiation effects (Figs. 2 and 3). The places where typical melting could be verified were rare. These characteristics were shown a little more evident in group A2 (Figs. 4 and 5).

In group $\mathrm{B}$, in which laser irradiation was applied perpendicular to the root canal walls, it was observed that laser action removed dentin pieces forming craters, that were covered by melted and recrystallized dentin in form of droplets (Figs. 6 and 7). These alterations presented similar characteristics in groups B1 and B2 and in group B2 the melting areas were more extensive (Figs. 8 and 9). In group B2, the effect of the laser light seemed to have reached deeper areas. As can be verified in Figures 7 and 8, the melted dentin appeared to be thicker and with altered conformation of the tubes, characterizing recrystallization of dentin that coated the dentin of root canal.

Morphological changes happened similarly in the cervical, middle, and apical thirds of groups B1 and B2.

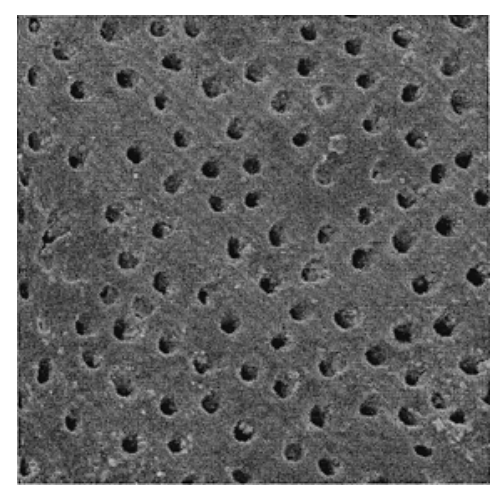

FIG. 3. Group A1 (circular/100 mJ, $15 \mathrm{~Hz}$, and $1.5 \mathrm{~W}$ ) cervical third $(2000 \times)$.

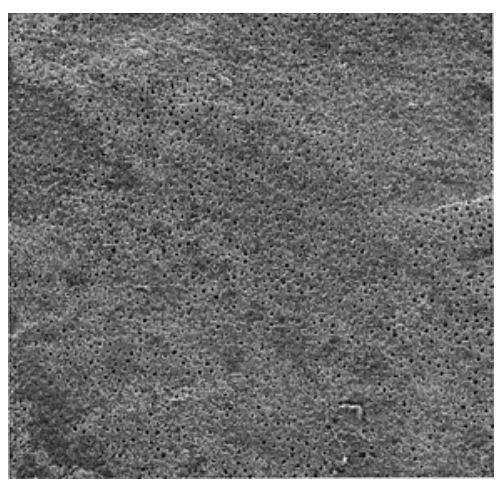

FIG. 4. Group A2 (circular/160 mJ, $15 \mathrm{~Hz}$, and $2.4 \mathrm{~W}$ ) cervical third $(5000 \times)$.

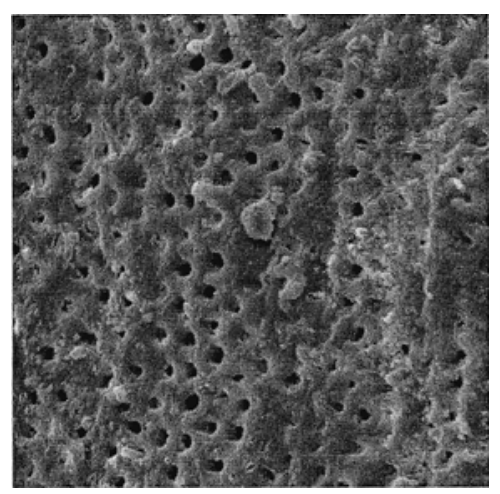

FIG. 5. Group A2 (circular/160 mJ, $15 \mathrm{~Hz}$, and $2.4 \mathrm{~W}$ ) cervical third $(2000 \times)$.

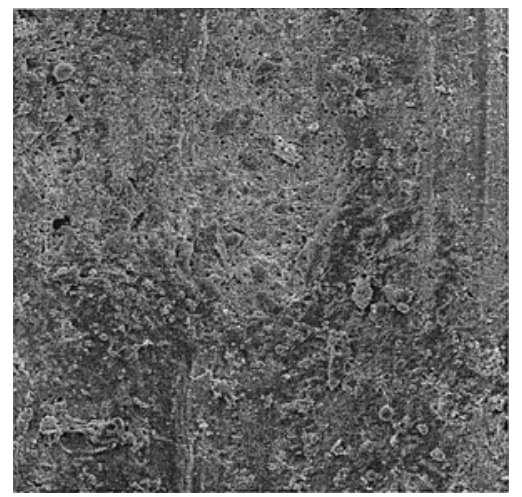

FIG. 6. Group B1 (perpendicular/100 mJ, 15 Hz, and $1.5 \mathrm{~W}$ ), middle third $(500 \times)$. 


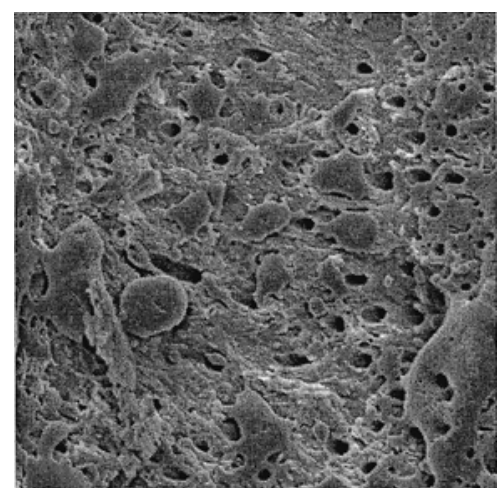

FIG. 7. Group B1 (perpendicular/100 mJ, $15 \mathrm{~Hz}$, and $1.5 \mathrm{~W}$ ), middle third $(2000 \times)$.

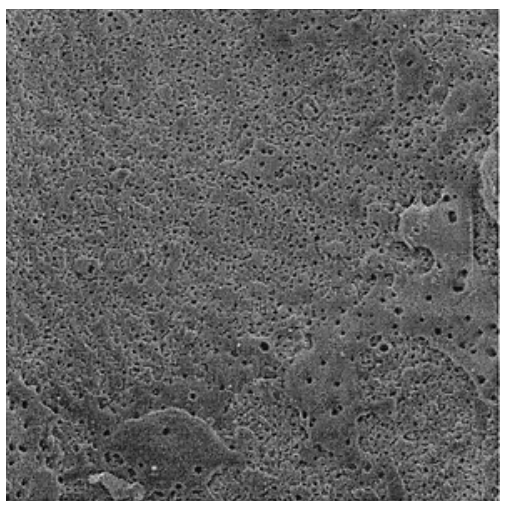

FIG. 8. Group B2 (perpendicular/ $160 \mathrm{~mJ}, 15 \mathrm{~Hz}$, and $2.4 \mathrm{~W}$ ), middle third $(500 \times)$.

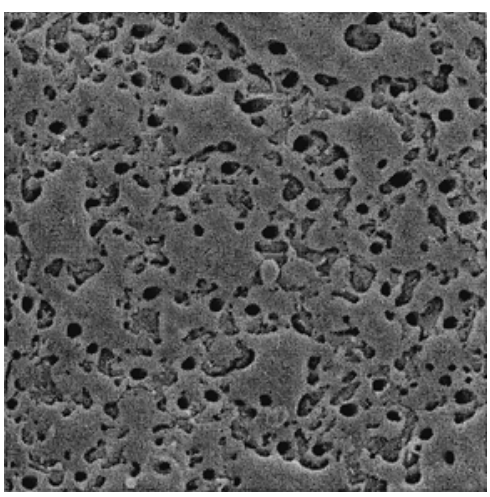

FIG. 9. Group B2 (perpendicular/160 mJ, $15 \mathrm{~Hz}$, and $2.4 \mathrm{~W}$ ), middle third $(2000 \times)$.
When comparing groups A (circular) and B (perpendicular), the statistical Kruskal-Wallis test showed significant differences ( $p=0.001$; A1 and A2 different from B1 and B2).

Dunn's test (5\%) showed that there were no statistical differences between the cervical, middle, and apical thirds.

\section{DISCUSSION}

The action of laser on the tissues depend on the wavelength, potency, pulse, time of exposure, and type of tissue to be irradiated. ${ }^{10,11}$

In Endodontics, for use into root canals or surgeries, Nd:YAG laser is the most common used. It can be used with antibacterial purpose, preparation of the root canal, debris removal, 5,9,11,12 vaporization of soft tissues, ${ }^{9,13}$ melting of hard tissues surface, ${ }^{11}$ and reduction of dentin permeability. 1,2,4,5,11,14,15

It is verified that after Nd:YAG laser application on the dentin, melting, recrystallization and glazing occur, with consequent reduction of the fluids permeability. ${ }^{1,15,16}$ Folwaczny et al., ${ }^{17}$ in 2002, suggested that use of the laser in the root canal walls leads to a reduction in the number of opened tubules, promoting a decrease of apical permeability, and this reduction in the permeability of the dentin walls can improve the sealing of root canal filling. ${ }^{7,15,18}$ However, the parameters used to provide these alterations are not yet established.

In this study, it was verified that when the energy of the laser light was altered with $100 \mathrm{~mJ}$ to $160 \mathrm{~mJ}$, few morphologic changes occurred, without significant differences for both forms of laser application (perpendicular and circular movements).

In 1992, Bahcall et al. ${ }^{16}$ demonstrated that there were no differences in the effects of dentin tubules obliteration in function of the energy variation of the Nd:YAG laser. Liu et al., ${ }^{20}$ in 1997, demonstrated that the energy of $30 \mathrm{~mJ}$ with 10 pulses/sec for 2 min provides morphological changes in dentin surface and dentin tubules occlusion. Lin et al., ${ }^{16}$ in 2001, and Lan et al., ${ }^{4}$ in 2000 , reported that the energy of $150 \mathrm{~mJ}$ was enough to promote the melting and dentin recrystallization.

Harashima et al., ${ }^{21}$ in 1997, using Nd:YAG laser with $1 \mathrm{~W}$ of potency verified debris and smear layer in the surface of root canal, covering the entrance of dentin tubules. With $2 \mathrm{~W}$, they verified the cleaning of walls with debris and smear layer evaporation, melting, coalition and recrystallization. Khan et al. ${ }^{3}$ also demonstrated that $2 \mathrm{~W}$ promoted the best results in the debris removal and morphological preservation of prepared root canal. Barbakow et al., ${ }^{22}$ in 1998, observed that higher laser energy provides carbonization areas. In the present study, it was verified that higher laser energy provides accentuated morphologic changes in root dentin. However, no statistical differences with the different parameters were found.

The effect of the Nd:YAG laser in root canal walls can be from an absence of morphological changes of dentin, occasional morphologic alterations in dentin walls, ${ }^{22}$ removal of smear layer, melting dentin recrystallization.1,12,19 The more frequent morphologic changes are dentin coalition, craters, 3,5,24,25 carbonization and glazing. ${ }^{3}$ Khan et al. ${ }^{3}$ observed that laser energy vaporized the debris, producing a glazed surface. However, in 1984, Dederich et al. ${ }^{1}$ verified that the Nd:YAG laser was unable to create a vitrified surface due to the melting of dentin, but was 
able to produce craters and perforations, due to dentin vaporization. In the present study, it was verified, especially in group B2, that laser application on the dentin provided great tissue melting identified that was identified as coalition and recrystallization inside dentin craters, as verified by other authors. $13,5,13,15,16,21,25$

Baraldi and Puricelli25 believe that these morphological changes of the dentin is probably because thermal damage provided by the excessive temperature that occurs in the Nd:YAG laser interaction with the tissue. It was observed that in groups A1 and A2, where the laser was applied simulating clinical conditions, there was predominance of areas with oblitered tubules and compact surface, without typical melting characteristic, as observed by Baraldi and Puricelli 25 in 2000.

In the present study, morphologic changes in the dentin surface promoted by the Nd:YAG laser applied perpendicular or parallel to the dentin surface were compared. Less significantly morphologic changes were found when the laser radiation was applied with circular movements (parallel to dentin surface) compared with the perpendicular application. The same could be verified in other studies in that perpendicular irradiation of the surface with Nd:YAG laser producing melting, recrystallization and vitrified surface covered by melted droplets. ${ }^{2,4,10}$ In the present study, dentin melting areas, recrystallization, surface with glaze aspect and sealing of dentin tubules could be observed after perpendicular application of the Nd:YAG laser. Anic et al., ${ }^{10}$ in 1998, verified that after the Nd:YAG laser irradiation, drops of melted dentin could be observed in the dentin surface where the laser fiber was in contact with the wall. After Nd:YAG laser application with the optic fiber in contact with dental tissues, Baraldi and Puricelli, ${ }^{25}$ in 2000, found melted surface and recrystallization, with rough and irregular aspect that was also verified in the present study.

Saunders et al. ${ }^{9}$ and Khan et al. ${ }^{3}$ believe that an advantage $\mathrm{Nd}$ :YAG laser is the fact that the opic fiber to be flexible, that allows an easy penetration in the root canal, also in areas with difficult access as the apical third. However, it was verified in the present study that laser action inside the root canal is limited.

In agreement with Zhang et al., ${ }^{11}$ Önal et al. ${ }^{8}$ the distribution of the laser energy along the root canal is heterogeneous. According to Anic et al., 6 Önal et al. 8 in the cervical third of the root, the coronary remainder leads a most perpendicular orientation of the fiber. On the other hand, at middle and apical thirds, the fiber is positioned parallel to the dentin walls. That difference in the orientation of the fiber provides different morphologic changes in a same root canal. These observations are in agreement with the present study, where the cervical and middle thirds presented more melting than the apical third, however without significant statistical differences. Goodis et al., ${ }^{23}$ in 1993, reported that $\mathrm{Nd}$ :YAG laser is only effective when there is contact with dentin walls, and verified that in cases where accessory canals exist the laser is not effective. On the contrary, Anic et al. ${ }^{6}$ have observed melting in secondary canals, demonstrating that the laser energy was reflected or transmitted by dentin tubules.

The formation of a smear layer can occurs during laser application in the root canal. However, Levy, ${ }^{15}$ in 1992, demonstrated that Nd:YAG laser promoted cleaning of the root canals avoiding debris formation.

Tani and Kawada, ${ }^{14}$ in 1987, Anic et al., ${ }^{6}$ in 1996, and Park et al., ${ }^{18}$ in 2001, verified that, in root canals where the smear layer was removed, there was no significant increase in dentin permeability after Nd:YAG laser application. In that same study, in the apical third of root canals, in which the smear layer was not removed, the melting and the recrystallization of the smear layer happened. ${ }^{6}$ Tani and Kawada, ${ }^{14}$ in 1987, and Baraldi and Puricelli, 25 in 2000, also verified that Nd:YAG laser was able to promote coalition and recrystallization of smear layer, and Zhang et al., ${ }^{11}$ in 1998, it also observed areas in that smear layer evaporation has occurred. Anic et al. ${ }^{10}$ reported that $\mathrm{Nd}$ :YAG laser induced erosion of smear layer.

Goodis et al. ${ }^{23}$ and Harashima et al. ${ }^{21}$ verified that Nd:YAG laser was able to remove the smear layer in its totality. On the other hand, Saunders et al., ${ }^{9}$ in 1995, verified that smear layer and debris removal from root canal after Nd:YAG laser application was not effective when compared with smear layer removal promoted by conventional preparation. According to this author, it was not possible to observe where there was the removal of smear layer and where there was not, because both situation presented similar aspects in the scanning electron microscopic. In the present study, the smear layer was removed before laser application; therefore, the effectiveness of laser was not evaluated on this layer.

\section{CONCLUSION}

Energy variation (100 or $160 \mathrm{~mJ}$ ) did not provide statistical differences in relation morphological changes in dentin walls. However, it was observed that perpendicular application to the dentin walls provides relevant morphologic changes in the dentin. More studies are required that evaluate parameters of laser irradiation and its consequences in laser therapy on root canals.

\section{REFERENCES}

1. Dederich, D.N., Zakariasen, K.L., Tulip, J., et al. (1984). Scanning electron microscopic analysis of root canal wall dentin following neodymium-yttrium-aluminum-garnet laser irradiation. J. Endod. 10:428-431.

2. Stabholz, A., Khayat, A., Ravanshad, S.H., et al. (1992). Effects of Nd:YAG laser on apical seal of teeth after apicoectomy and retrofill. J. Endod. 18:371-375.

3. Khan, M., Matsumoto, K., Wakabayashi, H., et al. (1997). Effect of laser treatment on the root canal of human teeth. Endod. Dent. Traumatol. 13:139-145.

4. Lan, W.H., Chen, K.W., Jeng, J.H., et al. (2000). A comparison of the morphological changes after Nd-YAG and $\mathrm{CO}_{2}$ laser irradiation of dentin surfaces. J. Endod. 26:450-453.

5. Miserendino, L.J., Levy, G.C., Rizoiu, L.M., et al. (1995). Effects of Nd:YAG laser on the permeability of root canal wall dentin. J. Endod. 21:83-87.

6. Anic, I., Tachibana, H., Matsumoto, K., et al. (1996). Permeability morphologic and temperature changes of canal dentin walls induced by Nd:YAG, $\mathrm{CO}_{2}$ and argon lasers. Int. Endod. J. 29:13-22.

7. Moriyama, E.H., Zangaro, R.A., Villaverde, A.B., et al. (2004). Dentin evaluation after Nd:YAG laser irradiation using short and long pulses. J. Clin. Laser Med. Surg. 22:43-50.

8. Önal, B., Siebert, T.E.G., Müller, G., et al. (1993). Preliminary report on the application of pulsed $\mathrm{CO}_{2}$ laser radiation on root canals 
with $\mathrm{AgC1}$ fibers: the scanning and transmission microscopic study. J. Endod. 19:272-276.

9. Saunders, W.P., Whitters, C.J., Strang, R., et al. (1995). The effect of an Nd:YAG pulsed laser on the cleaning of root canal and the formation of the fused apical plug. Int. Endod. J. 28:213-220.

10. Anic, I., Segovic, S., Katanec, D., et al. (1998). Scanning electron microscopic study of dentin laser with argon, $\mathrm{CO}_{2}$ and $\mathrm{Nd}$ :YAG laser. J. Endod. 24:77-81.

11. Zhang, C., Kimura, Y., Matsumoto, K., et al. (1998). Effects of pulsed Nd:YAG laser irradiation on root canal wall dentin with different laser initiators. J. Endod. 24:352-355.

12. Kaitsas, V., Signore, A., Fonzi, L., et al. (2001). Effects of Nd:YAG laser irradiation on the root canal wall dentin of human teeth: a SEM study. Bull. Group Int. Rech. Sci. Stomatol. Odontol. 43:87-92.

13. Barberini, A.F., Aun, C.E., Camargo, S.C.C., et al. (2001). Effects of intracanal irradiation with Nd:YAG laser. Mag. Odont. UNICID 13:183-188.

14. Tani, Y., and Kawada, H. (1987). Effects of laser irradiation on dentin. I. Effect on smear layer. Dent. Mater. J. 6:127-134.

15. Levy, G. (1992). Cleaning and shaping the root canal with Nd:YAG laser beam: the comparative study. J. Endod. 18:123-127.

16. Lin, C., Lee, B., Lin, F., et al. (2001). Phase, compositional, and morphological changes of human dentin after Nd:YAG laser treatment. J. Endod. 27:389-393.

17. Folwaczny, M., Mehl, A., Jordan, C., et al. (2002). Antibacterial effects of pulsed Nd:YAG laser radiation at different energy settings in root canals. J. Endod. 28:24-29.

18. Park, D.S., Lee, H.J., Yoo, H,.M., et al. (2001). Effect of Nd:YAG laser irradiation on the apical leakage of obturated root canals: an electrochemical study. Int. Endod. J. 34:318-321.
19. Bahcall, J., Howard, P., Miserendino, L., et al. (1992). Preliminary investigation of the histological effect of laser endodontic treatment on the perpendicular tissues in dogs. J. Endod. 18:47-51.

20. Liu, H., Lin, C., and Lan, W. (1997). Sealing depth of Nd:YAG laser on human dentinal tubules. J. Endod. 23:691-693.

21. Harashima, T., Takeda, F.H., Kimura, Y., et al. (1997). Effect of Nd:YAG laser irradiation on removal of intracanal debris and smear layer in extracted human teeth. J. Clin. Laser Med. Surg. 15:131-135.

22. Barbakow, F., Lutz, F., and Havraneck, L. (1998). Without and microscope evaluation of Nd:YAG lased root canal walls. J. Endod. $24: 276$.

23. Goodis, H.E., White, J.M., Marshall, S.J., et al. (1993). Scanning electron microscopic examination of intracanal wall dentin: hand versus laser treatment. Scanning Microsc. 7:979-987.

24. Myers, M.L. (1991). The effect of laser irradiation on oral tissues. J. Prosthet. Dent. 66:395-397.

25. Baraldi, C.E., and Puricelli, E. (2000). Study in vitro of the morphologic alterations of the surface of roots submitted to the apicectomy and irradiated with laser of Nd:YAG. Mag. Odont. Porto Alegre 40:29-34.

Address reprint requests to:

Dr. Marcia Carneiro Valera

Av. Francisco José Longo, 777

Faculdade de Odontologia de São José dos Campos-UNESP

Caixa Postal 314

São José dos Campos, SP, Brazil, CEP 12201-970

E-mail: samiraafonso@uol.com.br 